\title{
Pull-through method for central venous catheter placement in a case of cadaveric donor small bowel retransplantation
}

\author{
Kayo Kimura, Shuji Kawamoto* ${ }^{*}$, Shinichi Kai, Tomoharu Tanaka and Kazuhiko Fukuda
}

Keywords: Cadaveric donor small bowel transplantation, Retransplantation, Difficulty securing the central venous route, Pull-through method

To the Editor,

Small bowel transplantation is indicated in patients with short bowel syndrome or irreversible small bowel insufficiency who have progressive liver dysfunction or difficulty with securing the central venous route after long-term intravenous feeding $[1,2]$. We report the fifth case of cadaveric donor small bowel retransplantation in Japan [3], in which a central venous route was secured using the pull-through method.

The patient was a 22-year-old female with a height of $131.3 \mathrm{~cm}$ and a weight of $30.9 \mathrm{~kg}$. Intravenous feeding was started due to small bowel insufficiency of unknown cause after birth. The catheter had to be changed due to frequent infections, and it became increasingly difficult to secure the central venous route. Her first cadaveric donor small bowel transplantation was performed at age of 13. The transplanted small bowel gradually became dysfunctional due to chronic rejection, and intravenous feeding was planned to be reintroduced, but the central venous route was already depleted. A Broviac catheter was inserted percutaneously and transhepatically through the left hepatic vein. Cadaveric donor small bowel retransplantation was determined to be indicated.
The establishment of a central venous route was essential for her perioperative management. Contrast-enhanced computed tomography showed slight patency in the left internal jugular vein. We punctured the left internal jugular vein, and a guidewire was advanced with ultrasound guidance under local anesthesia. However, there was a stenosis in the innominate vein, and the catheter could not be advanced beyond that. We decided to try the pull-through method, which is useful for inserting a catheter into a narrow or tortuous vessel. By using this method, sufficient tension can be applied to the guidewire, which allows the catheter to be stably advanced to a target site $[4,5]$. In this case, the snare wire was advanced retrograde through the right inferior hepatic vein with ultrasound guidance under local anesthesia without sedation and passed through the innominate vein stenosis. The guidewire inserted from the left internal jugular vein was captured by the snare wire and withdrawn from the right inferior hepatic vein outside the body. The guidewire was firmly tensioned from the cephalad and caudal sides, and the catheter could be placed through the left internal jugular vein (Fig. 1). Percu-

\footnotetext{
* Correspondence: skawamot@kuhp.kyoto-u.ac.jp

Department of Anesthesia, Kyoto University Hospital, 54,

Shogoinkawahara-cho, Sakyo-ku, Kyoto 606-8507, Japan
}

Springer Open

(c) The Author(s). 2021 Open Access This article is licensed under a Creative Commons Attribution 4.0 International License, which permits use, sharing, adaptation, distribution and reproduction in any medium or format, as long as you give appropriate credit to the original author(s) and the source, provide a link to the Creative Commons licence, and indicate if changes were made. The images or other third party material in this article are included in the article's Creative Commons licence, unless indicated otherwise in a credit line to the material. If material is not included in the article's Creative Commons licence and your intended use is not permitted by statutory regulation or exceeds the permitted use, you will need to obtain permission directly from the copyright holder. To view a copy of this licence, visit http://creativecommons.org/licenses/by/4.0/. 

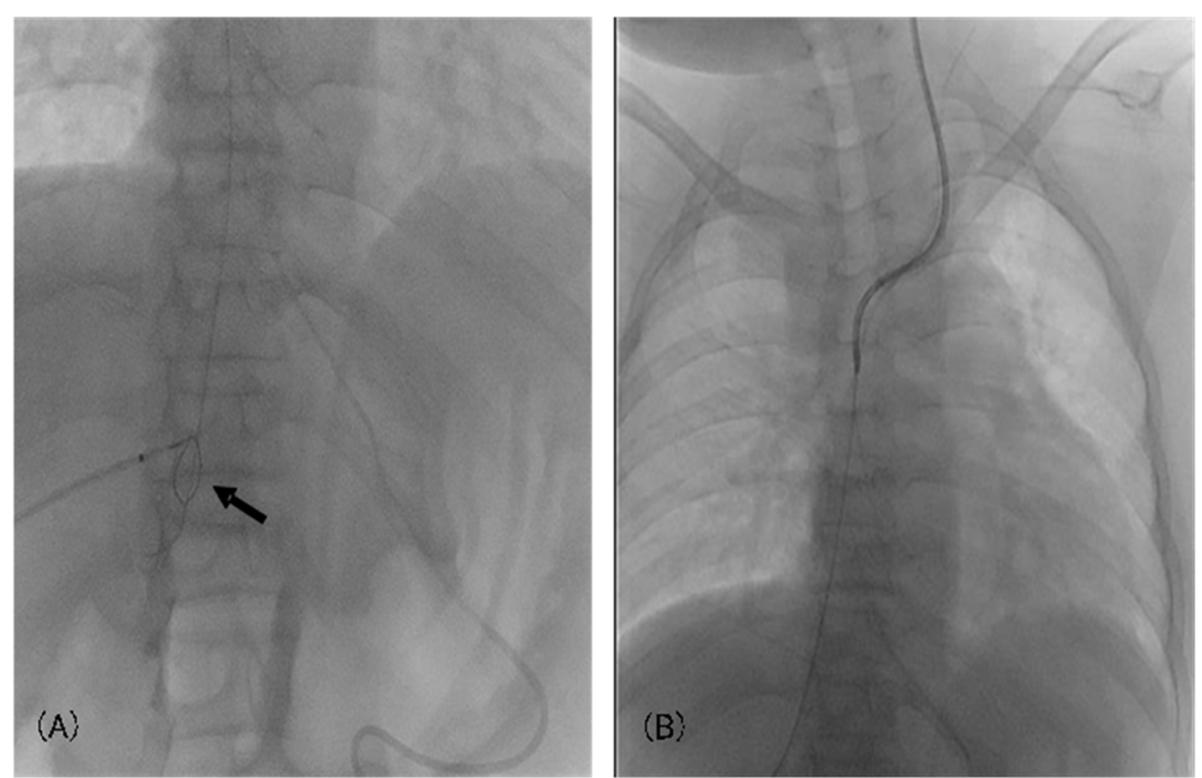

Fig. 1 A central venous catheter placement using the pull-through method. A snare wire (arrow) was used to capture the inserted wire from the left internal jugular vein and pulled out of the right inferior hepatic vein outside the body (a). A central venous catheter was inserted through the left internal jugular vein (b)

taneous transhepatic tract embolization was performed after the procedure. This catheter and the percutaneous transhepatic Broviac catheter were used as venous routes during the perioperative period (Fig. 2).

Central venous routes from the internal thoracic vein, intercostal vein, inferior abdominal wall vein, hepatic vein, and gonadal vein have been used in cases of obstruction or stenosis of major vessels. However, most such reports have been in pediatric cases [6-8]. A hepatic venous approach by ultrasound-

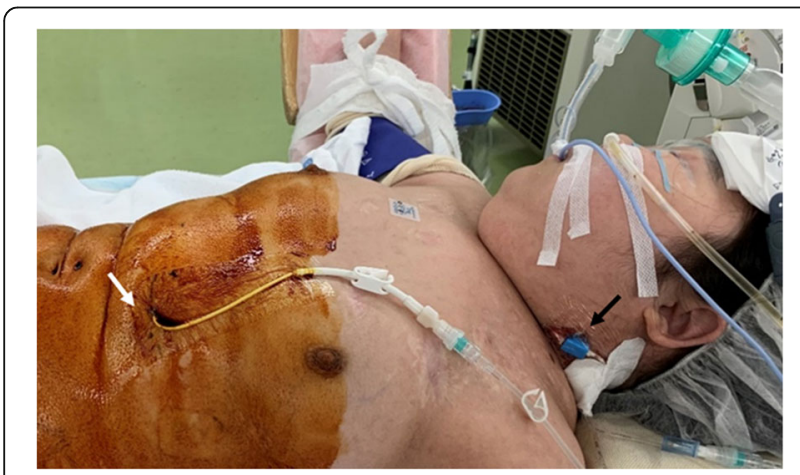

Fig. 2 A photograph after the induction of anesthesia. A Broviac catheter is placed in the left hepatic vein (white arrow), and a central venous catheter is placed in the left internal jugular vein (black arrow) guided percutaneous transhepatic puncture has also been reported [9]. The technique is relatively safe, like percutaneous transhepatic biliary drainage, and the risk of bleeding is low; however, general anesthesia is required for the placement. In contrast, securing the central venous route via the internal jugular vein using the pull-through method can be performed under local anesthesia. We suggest that this is a useful option in cases where the central venous route is difficult to secure.

\section{Acknowledgements}

Not applicable.

\section{Authors' contributions}

KK wrote the initial draft of the manuscript. SK $K_{1}$ and KK performed the perioperative management. $\mathrm{SK}_{1}$ was the attending anesthesiologist for the case. $\mathrm{SK}_{1}$ supervised the perioperative management. $\mathrm{SK}_{2}$ and $\Pi \mathrm{T}$ managed the patient in the ICU. SK ${ }_{1}, \mathrm{SK}_{2}, \mathrm{TT}$, and $\mathrm{KF}$ drafted and edited the manuscript. All authors read and approved the final manuscript.

\section{Funding}

Institutional sources only.

\section{Availability of data and materials}

All data generated or analyzed in this study are included in this article.

\section{Ethics approval and consent to participate Not applicable.}

\section{Consent for publication}

Written consent was obtained from the parent of the patient for the publication of this case report. 


\section{Competing interests}

The authors declare that they have no competing interests.

Received: 26 October 2020 Revised: 28 December 2020

Accepted: 2 January 2021 Published online: 12 January 2021

\section{References}

1. Kesseli S, Sudan D. Small bowel transplantation. Surg Clin North Am. 2019; 99:103-16.

2. Mittal NK, Tzakis AG, Kato T, Thompson JF. Current status of small bowel transplantation in children. Pediatr Clin N Am. 2003:50:1419-33.

3. Factbook on 2019 Organ Transplantation in Japan. http://www.asas.or.jp/jst/ pdf//factbook2019.pdf Accessed 13 Oct 2020.

4. Loose HW, Ryall CJ. Common iliac artery occlusion: treatment with pullthrough angioplasty. Radiology. 1988;168:273-4.

5. Nazarian GK, Myers TV, Bjarnason H, Stackhouse DJ, Dietz CA, Hunter DW. Application of the Amplatz snare device during interventional radiologic procedures. Am J Roentgenol. 1995;165:673-8.

6. Tannuri U, Tannuri AC, Maksoud JG. The second and third right posterior intercostal veins: an alternate route for central venous access with an implantable port in children. J Pediatr Surg. 2005;40:27-30.

7. Saleh HM, Abdelaziz AS, Hefnawy E, Mansour O. Alternate routes for children with difficult central venous access. Acta Chir Belg. 2008;108:563-8.

8. Rodrigues AF, van Mourik IDM, Sharif K, Barron DJ, de Giovanni JV, Bennett J, Bromley P, Protheroe S, John P, de Ville de Goyet J, Beath SV. Management of end-stage central venous access in children referred for possible small bowel transplantation. J Pediatr Gastroenterol Nutr. 2006;42: 427-33.

9. Crummy AB, Carlson P, McDermott JC, Andrews D. Percutaneous transhepatic placement of a Hickman catheter. Am J Roentgenol. 1989;153: 1317-8.

\section{Publisher's Note}

Springer Nature remains neutral with regard to jurisdictional claims in published maps and institutional affiliations.

\section{Submit your manuscript to a SpringerOpen ${ }^{\circ}$ journal and benefit from:}

- Convenient online submission

- Rigorous peer review

- Open access: articles freely available online

- High visibility within the field

- Retaining the copyright to your article 